\title{
OPEN Extended-spectrum $\beta$-lactamase-producing Escherichia coli isolated from raw vegetables in South Korea
}

\begin{abstract}
Jihyun Song ${ }^{1}$, Sung-Suck $\mathrm{Oh}^{2}$, Junghee $\mathrm{Kim}^{2}$ \& Jinwook Shin ${ }^{1 \bowtie}$
The increasing prevalence of oxyimino-cephalosporin-resistant Enterobacteriaceae has become a global concern because of their clinical impact on both human and veterinary medicine. The present study determined the prevalence, antimicrobial susceptibility, and molecular genetic features of extended-spectrum $\beta$-lactamase (ESBL)-producing Escherichia coli (ESBL-EC) isolates from raw vegetables. A total of 1324 samples were collected from two agricultural wholesale markets in Incheon, South Korea in 2018. The ESBL-EC strains were isolated from $0.83 \%(11 / 1324)$ samples, and all of them were resistant to ampicillin, piperacillin, cefazoline, cefotaxime, and nalidixic acid and yielded CTX-M-type ESBL, including CTX-M-14, CTX-M-15, CTX-M-55, CTX-M-27, and CTX-M-65. The isolates belonged to phylogenetic subgroups $D(n=5), A(n=4)$, and $B 1(n=2)$. Multilocus sequence typing revealed nine known $E$. coli sequence types (STs), including ST10, ST38, ST69, ST101, ST224, ST349, ST354, ST2509, ST2847, and two new STs. Notably, ST69, ST10, ST38, and ST354 belong to the major human-associated extraintestinal pathogenic $E$. coli lineages. Our results demonstrate that ESBL-producing multidrug-resistant pathogens may be transmitted to humans through the vegetable intake, highlighting the importance of resistance monitoring and intervention in the One Health perspective.
\end{abstract}

Gram-negative bacteria produce extended-spectrum $\beta$-lactamases (ESBLs) that are primarily responsible for resistance to oxyimino-cephalosporins such as cefotaxime. Among the ESBLs, the plasmid-mediated CTX-Mtype enzymes have become predominant worldwide ${ }^{1,2}$. Based on the sequence identity of amino acids, five distinct groups of CTX-M-type enzymes (CTX-M-1, -2, -8, -9, and -25 groups) and more than 214 CTX-M-type enzymes have been reported (ftp://ftp.ncbi.nlm.nih.gov/pathogen/Antimicrobial_resistance; accessed January 24, 2020). In South Korea, many studies have been reported on ESBL-producing Escherichia coli strains (ESBL-ECs) in hospital and community settings since the first identification of CTX-M-14 in clinical isolates of E. coli, Shigella sonnei, and Klebsiella pneumoniae in $2001^{3}$. According to the national antimicrobial resistance surveillance system, the resistance rates for cefotaxime in clinical E. coli isolates increased gradually from $29 \%$ in 2013 to $35 \%$ in $2017^{4,5}$. Among the clinical isolates of ESBL-ECs, CTX-M-14 was the dominant type of ESBLs, and sequence type (ST) 131 accounted for more than $20 \%$ of them ${ }^{6-11}$. The prevalence of E. coli producing CTX-M-type ESBLs in healthy Korean adults was $8.3 \%$ in $2014^{12}$.

Besides humans, ESBL-ECs have been isolated from livestock, food, the environment, and other non-human sources ${ }^{13-16}$. It has been reported that animals can be a primary reservoir of ESBL-ECs ${ }^{17}$ and that foods may play a role in the dissemination of resistance to humans through the food chain ${ }^{18-20}$. For this reason, several developed countries have implemented antimicrobial resistance monitoring programs for food products, as well as in humans and animals based on the One Health approach ${ }^{21}$. A number of studies conducted in South Korea have also documented the prevalence of ESBL-ECs in multiple sectors, including livestock (chickens, $94.1 \%$; pigs, $69.5 \%$; cattle, $7.0 \%)^{22}$, imported meat $(1.1 \%)^{23}$, companion animals $(44.7 \%)^{24}$, ready-to-eat sprouts $(3.3 \%)^{25}$, and river water $(2.5 \%)^{26}$. Despite posing a high risk of transmission to humans through direct intake, few studies have been conducted on vegetable ESBL-ECs, so the available data is limited. Here, we investigated the prevalence, antimicrobial susceptibilities, responsible genes, and clonal lineages of ESBL-ECs isolated from raw vegetables in South Korea according to a nationwide surveillance program.

${ }^{1}$ Department of Microbiology, Inha University College of Medicine, 100 Inha-ro, Nam-gu, Incheon 22212, South Korea. ${ }^{2}$ Incheon Research Institute of Public Health and Environment, Incheon 22320, South Korea. ${ }^{\square}$ email: shin001@inha.ac.kr 


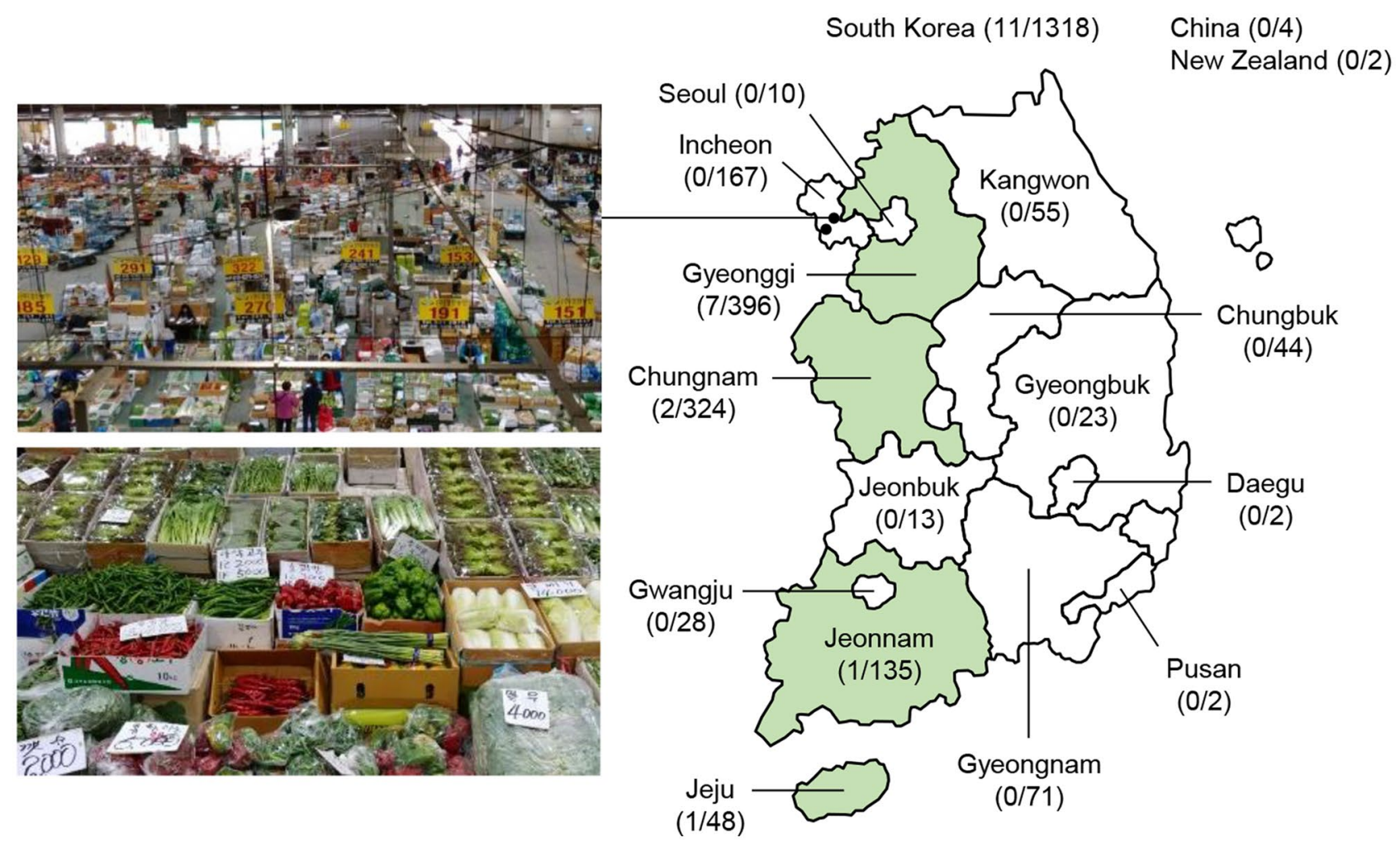

Figure 1. National wide distribution of cefotaxime-resistant $E$. coli isolates from vegetables. The black circle and green area represented the location of the wholesale market for agricultural products from which vegetables were collected and the production site of them from which resistance was detected, respectively. The map was generated by using software program Microsoft PowerPoint 2016.

\section{Results}

Prevalence and antimicrobial susceptibility. Among 1324 raw vegetable samples, a total of 11 nonduplicate cefotaxime-resistant ESBL-ECs were recovered from the stem $(5 / 170,2.94 \%)$ and leafy $(6 / 879,0.68 \%)$ vegetables (Fig. 1 and Table 1). No ESBL-ECs were isolated from the fruit and root types of vegetables. Antimicrobial susceptibility testing showed that all eleven isolates were resistant to ampicillin, piperacillin, cefazoline, cefotaxime, and nalidixic acid but susceptible to amikacin, ertapenem, imipenem, meropenem, tigecycline, and colistin (Table 1). The non-susceptibility rates for trimethoprim-sulfamethoxazole, aztreonam, ciprofloxacin, tetracycline, chloramphenicol, and gentamicin were $81.8 \%, 81.8 \%, 72.7 \%, 72.7 \%, 54.5 \%$, and $45.5 \%$, respectively. All of the isolates showed multidrug-resistant (MDR) phenotypes.

Characterization of $\beta$-lactamase genes. All of the isolates carried either $b$ la $_{\mathrm{CTX} \text {-M }}$ group $1(5 / 11,45.5 \%)$ or $b l a_{\text {СТХ-м }}$ group $9(6 / 11,54.5 \%)$ genes, including $b l a_{\mathrm{CTX}-\mathrm{M}-15}(\mathrm{n}=3), b l a_{\mathrm{CTX-M-14}}(\mathrm{n}=3), b l a_{\mathrm{CTX}-\mathrm{M}-55}(\mathrm{n}=2)$, $b l a_{\mathrm{CTX}-\mathrm{M}-27}(\mathrm{n}=2)$, and $b l a_{\mathrm{CTX}-\mathrm{M}-65}(\mathrm{n}=1)$ (Table 1$)$. The $b l a_{\mathrm{CTX}-\mathrm{M}-27}$ and $b l a_{\mathrm{CTX}-\mathrm{M}-65}$ were found only in the leafy vegetable isolates. Five isolates co-carried the non-ESBL gene $b l a_{\mathrm{TEM}-1}$.

Phylogenetic groups and MLST. The phylogenetic analysis revealed that the ESBL-ECs belonged to subgroups D (5/11, 45.5\%), A (4/11,36.4\%), and B1 (2/11, 18.2\%) (Table 1). Two isolates belonging to subgroup B1 were detected only in stem vegetables. MLST analysis demonstrated that all of the isolates were assigned to different STs, including ST10, ST38, ST69, ST101, ST224, ST349, ST354, ST2509, ST2847, and two new STs. The allele codes for the new STs differed from ST6764 (allele code 10-11-5-10-12-8-6) by the mdh locus, ST1251 (6-27-4-10-8-8-6) and ST4967 (6-27-4-350-8-8-6) by the icd locus (Fig. 2). The MLST-based phylogenetic tree showed two major clusters, among which Cluster I comprised $85.7 \%$ commensal subgroups A and B1, and Cluster II was comprised only the virulent subgroup D (Fig. 2). There was no distributional difference between the clusters in leafy and stem vegetable isolates.

\section{Discussion}

Fresh produce is usually consumed raw or not properly heated. Consequently, a considerable portion of recent foodborne outbreaks has been attributed to fresh produce contaminated by pathogens ${ }^{27}$. Likewise, antimicrobial resistance can readily spread to humans through the vegetables contaminated with resistant bacteria. ESBL-ECs have also been found in vegetables, principally ready-to-eat vegetables ${ }^{19,25}$ and raw vegetables ${ }^{28-32}$. In this study, we isolated the cefotaxime-resistant ESBL-ECs from eleven $(0.83 \%)$ of 1324 raw vegetables, indicating a lower 


\begin{tabular}{|c|c|c|c|c|c|c|c|c|c|c|c|c|c|c|c|c|c|c|c|c|c|c|c|c|c|c|c|c|}
\hline \multirow[b]{2}{*}{ Isolate } & \multirow[b]{2}{*}{ Vegetable } & \multirow[b]{2}{*}{ Type } & \multirow[b]{2}{*}{ Province } & \multirow{2}{*}{$\begin{array}{l}\text { Phylo } \\
\text { group }\end{array}$} & \multirow[b]{2}{*}{ ST } & \multirow[b]{2}{*}{$\beta$-lactamase } & \multicolumn{22}{|c|}{ Antimicrobial agent, disk agar diffusion zone diameter $(\mathrm{mm})$, and colistin MIC $(\mu \mathrm{g} / \mathrm{mL})$} \\
\hline & & & & & & & GEN & AMK & ETP & IPM & MEM & CFZ & CTX & CAZ & FEP & FOX & CIP & NAL & SXT & TGC & ATM & AMP & PIP & AMC & SAM & $\mathrm{CHL}$ & TET & CST \\
\hline EC001 & Cabbage & Leafy & Jeonnam & D & 2847 & CTX-M-65 & 19.4 & 20.0 & 30.8 & 27.6 & 29.8 & 7.0 & 12.3 & 25.4 & 24.1 & 23.4 & 11.0 & 6.0 & 7.0 & 22.1 & 17.2 & 6.0 & 14.1 & 23.0 & 19.1 & 6.0 & 6.0 & 0.5 \\
\hline EC048 & $\begin{array}{l}\text { Water } \\
\text { parsley }\end{array}$ & Stem & Gyeonggi & A & New & CTX-M-55 & 20.3 & 21.0 & 29.2 & 31.1 & 32.5 & 7.0 & 9.0 & 21.8 & 21.0 & 20.2 & 19.1 & 6.0 & 21.0 & 23.7 & 16.1 & 6.0 & 15.0 & 22.8 & 18.8 & 6.0 & 6.0 & 0.5 \\
\hline EC049 & $\begin{array}{l}\text { Aster } \\
\text { Scaber }\end{array}$ & Leafy & Jeju & D & 69 & $\begin{array}{c}\text { CTX-M-14, } \\
\text { TEM-1 }\end{array}$ & 20.1 & 20.8 & 31.0 & 27.7 & 31.5 & 7.0 & 16.9 & 26.4 & 25.0 & 24.4 & 12.2 & 6.0 & 7.0 & 23.9 & 23.3 & 6.0 & 12.5 & 20.0 & 16.4 & 26.6 & 6.0 & 1.0 \\
\hline EC053 & Perilla leaf & Leafy & Chungnam & D & 349 & $\begin{array}{c}\text { CTX-M-27, } \\
\text { TEM-1 }\end{array}$ & 22.0 & 23.4 & 27.6 & 27.5 & 30.4 & 6.0 & 6.0 & $|14.7|$ & 16.1 & 22.1 & 24.2 & 6.0 & 6.0 & 25.3 & 11.5 & 6.0 & 6.0 & 13.9 & 7.8 & 27.7 & 23.4 & 0.5 \\
\hline EC054 & $\begin{array}{l}\text { Water } \\
\text { parsley }\end{array}$ & Stem & Gyeonggi & B1 & 101 & $\begin{array}{l}\text { CTX-M-15, } \\
\text { TEM-1 }\end{array}$ & 6.0 & 23.0 & 29.9 & 28.3 & 31.1 & 6.0 & 8.9 & 22.7 & 21.7 & 22.5 & 25.8 & 6.0 & 6.0 & 23.0 & $|17.0|$ & 6.0 & 9.3 & 19.4 & 17.1 & 6.0 & 6.0 & 0.5 \\
\hline EC058 & Pepper leaf & Leafy & Gyeonggi & A & New & $\begin{array}{l}\text { CTX-M-55, } \\
\text { TEM-1 }\end{array}$ & 7.0 & 22.5 & 30.8 & 29.3 & 31.0 & 6.0 & 8.9 & 20.5 & 19.6 & 22.4 & $\mid 11.2$ & 6.0 & 6.0 & 22.5 & $|15.6|$ & 6.0 & 9.9 & 16.5 & 14.0 & 6.0 & 6.0 & 1.0 \\
\hline EC094 & $\begin{array}{l}\text { Water } \\
\text { parsley }\end{array}$ & Stem & Gyeonggi & D & 354 & $\begin{array}{l}\text { CTX-M-14, } \\
\text { TEM-1 }\end{array}$ & 6.0 & 21.6 & 30.1 & 30.6 & 34.0 & 6.0 & 11.8 & 26.3 & 22.9 & 17.0 & 6.0 & 6.0 & 6.0 & 24.0 & $\mid 16.2$ & 6.0 & 13.6 & 16.0 & 11.8 & 21.7 & 6.0 & 0.5 \\
\hline EC130 & \begin{tabular}{c|} 
Sweet \\
potato stalk
\end{tabular} & Stem & Chungnam & B1 & 224 & СTX-M-15 & 10.0 & 21.0 & 33.0 & 28.0 & 32.0 & 6.0 & 6.0 & 20.0 & 19.0 & 22.0 & 6.0 & 6.0 & 6.0 & 25.0 & $|15.0|$ & 6.0 & 9.0 & 20.0 & $|17.0|$ & $|11.0|$ & 6.0 & 1.0 \\
\hline EC131 & $\begin{array}{l}\text { Water } \\
\text { parsley }\end{array}$ & Stem & Gyeonggi & D & 38 & СТX-M-14 & 20.0 & 22.0 & 28.0 & 28.0 & 30.0 & 6.0 & 10.0 & 25.0 & 19.0 & 21.0 & 6.0 & 6.0 & 6.0 & 23.0 & 19.0 & 6.0 & 9.0 & 15.0 & 14.0 & 28.0 & 26.0 & 0.5 \\
\hline EC132 & Lettuce & Leafy & Gyeonggi & A & 2509 & CTX-M-15 & 6.0 & 22.0 & 31.0 & 30.0 & 32.0 & 6.0 & 11.0 & 20.0 & 18.0 & 24.0 & 6.0 & 6.0 & 19.0 & 23.0 & 13.0 & 6.0 & 11.0 & 21.0 & 16.0 & 6.0 & 25.0 & 0.5 \\
\hline EC134 & $\begin{array}{l}\text { Mapleleaf } \\
\text { ainsliaea }\end{array}$ & Leafy & Gyeonggi & A & 10 & CTX-M-27 & 21.0 & 22.0 & 34.0 & 28.0 & 31.0 & 6.0 & 12.0 & 23.0 & 23.0 & 26.0 & 27.0 & 6.0 & 6.0 & 26.0 & 22.0 & 6.0 & 13.0 & 22.0 & $\left.20.0\right|^{2}$ & 27.0 & 6.0 & 1.0 \\
\hline
\end{tabular}

Table 1. Characteristics of 11 cefotaxime-resistant E. coli isolates from vegetables. The colors of pink and yellow indicated resistant and intermediate resistant to corresponding agents, respectively. The allele codes of the two new STs were $a d k(6)$, fumC (27), gyrB (4), icd (New), $m d h$ (8), purA (8), and recA (6) for EC048 and adk (10), fumC (11), gyrB (5), icd (10), $m d h$ (11), purA (8), and recA (6) for EC058. ST, sequence type; MIC, minimum inhibitory concentration; GEN, gentamicin; AMK, amikacin; ETP, ertapenem; IPM, imipenem; MEM, meropenem; CFZ, cefazolin; CTX, cefotaxime; CAZ, ceftazidime; FEP, cefepime; FOX, cefoxitin; CIP, ciprofloxacin; NAL, nalidixic acid; SXT, trimethoprim-sulfamethoxazole; TGC, tigecycline; ATM, aztreonam; AMP, ampicillin; PIP, piperacillin; AMC, amoxicillin-clavulanic acid; SAM, ampicillin-sulbactam; CHL, chloramphenicol; TET, tetracycline; CST, colistin.

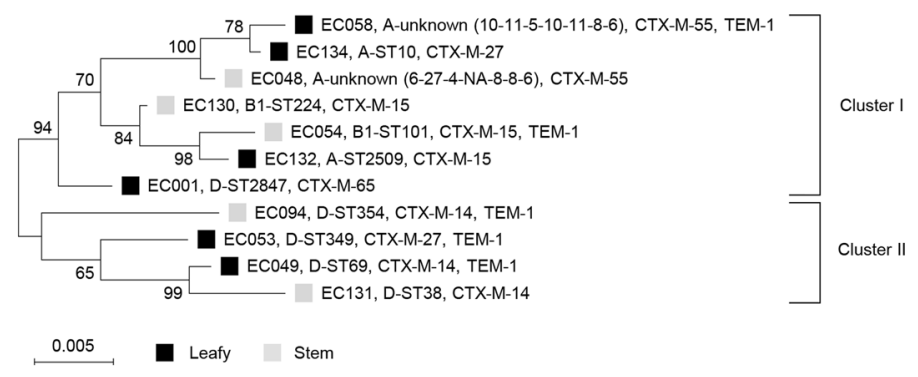

Figure 2. Phylogenetic tree of cefotaxime-resistant E. coli isolates from leafy and stem vegetables. Black and gray squares represented leafy and stem vegetables, respectively. Bootstrap support percentages were indicated in the different branches. Scale bar represented the genetic distance. Allele codes (adk-fumC-gyrB-icd-mdhpurA-recA) for new STs were indicated. NA, not assigned.

prevalence than that documented in a previous report on ready-to-eat sprouts $(3 / 91,3.3 \%)$ in South Korea ${ }^{25}$. The prevalence was about four times higher in the stem-type $(2.94 \%)$ than the leafy-type samples $(0.68 \%)$, but no isolates were detected in fruit and root types.

All 11 ESBL-ECs from vegetables in this study were MDR strains with resistance to ampicillin, piperacillin, cefazoline, cefotaxime, and nalidixic acid. Similarly, resistance to ampicillin, cefazoline, and cefotaxime were also reported on livestock and human ESBL-ECs in South Korea ${ }^{8,22}$. In addition, all of the vegetable isolates were susceptible to amikacin and tigecycline, which was consistent with previous reports in clinical isolates ${ }^{33,34}$.

Global epidemiology indicates that $b l a_{\text {СтХ-М-15 }}$ is the most prevalent ESBL gene worldwide ${ }^{2}$. Besides South Korea, however, $b l a_{\text {CTX-м }}$ group 9 (especially $b l a_{\text {СTX-M-14 }}$ ) variants are dominant in China, South-East Asia, Japan, and Spain ${ }^{2,7,8}$. bla $a_{\mathrm{CTX-M-27}}$ has been reported as the most common bla $a_{\mathrm{CTX}-\mathrm{M}}$ genotype in E. coli among patients in Vietnam ${ }^{35}$. All of the isolates from vegetables in this study harbored various $b l a_{\text {СTX-M }}$ genes, which include $b l a_{\mathrm{CTX}-\mathrm{M}-14}, b l a_{\mathrm{CTX}-\mathrm{M}-15}, b l a_{\mathrm{CTX}-\mathrm{M}-55}, b l a_{\mathrm{CTX}-\mathrm{M}-65}$, and $b l a_{\mathrm{CTX}-\mathrm{M}-27}$, representing the most common ESBL types worldwide. The presence of $b l a_{\mathrm{CTX}-\mathrm{M}-55}, b l a_{\mathrm{CTX}-\mathrm{M}-65}$, and $b l a_{\mathrm{CTX}-\mathrm{M}-27}$ has also been noted in E. coli isolated from humans, animals, and retail meat in South Korea ${ }^{7,8,22,24,36-38}$ as well as in neighboring countries, including $\mathrm{China}^{39,40}$ Japan $^{41,42}$, and Vietnam ${ }^{43}$. Despite the small number of $E$. coli isolates from different types of vegetables, the ESBL genotypes have been reported to be geographically distinct. The main types are $b l a_{\mathrm{CTX}-\mathrm{M}-15}$ in the Dominican Republic ${ }^{30}$, India ${ }^{30}$, and Ecuador ${ }^{28}$, bla $_{\text {CTX-M-14 }}$ in South Africa ${ }^{31}, b l a_{\text {CTX-M-55 }}$ in Thailand ${ }^{30}$, and $b l a_{\mathrm{CTX-M-65}}$ in Vietnam ${ }^{30}$. In South Korea, $b l a_{\text {СтХ-М-55 }}$ and $b l a_{\mathrm{CTX-M-14}}$ were found in $E$. coli isolates from readyto-eat sprouts between 2012 and $2013^{25}$, and $b l_{\text {CTX-M-55 }}$ was also detected in the colistin-resistant E. coli ST10 
from lettuce in $2018^{44}$. In particular, the population of ESBL-ECs harboring $b l a_{\mathrm{CTX}-\mathrm{M}-55}$ has noticeably increased in both humans and animals in China ${ }^{45,46}$ and Vietnam ${ }^{43}$. In this study, we also identified $b l a_{\mathrm{CTX}-\mathrm{M}-55^{-}}$-harboring ESBL-ECs from $18.2 \%(2 / 11)$ of raw vegetables. Given that CTX-M-55 is a variant of CTX-M-15 with a single amino acid substitution of $A 77 \mathrm{~V}^{47}$, our results and those of previous investigators suggest that CTX-M-55 may be replacing CTX-M-15, particularly in Asia.

E. coli phylogenetic groups A and B1 are typically commensal strains, whereas the B2 and D groups are mainly extraintestinal virulent strains ${ }^{48}$. In our study, the proportions were comparable between these commensal $(6 / 11,54.5 \%)$ and more virulent $(5 / 11,45.5 \%)$ lineages. MLST analysis revealed 11 different STs for the 11 ESBL-ECs in this study. Interestingly, four isolates $(4 / 11,36.4 \%)$ belonging to ST69, ST354, ST38, and ST10 were among the top 20 global extraintestinal pathogenic E. coli (ExPEC) lineages ${ }^{49}$, which are responsible for the majority of extraintestinal diseases, such as urinary tract infection, sepsis, and neonatal meningitis, and may have food animal sources ${ }^{50}$. These E. coli STs have been also observed in humans and livestock in South

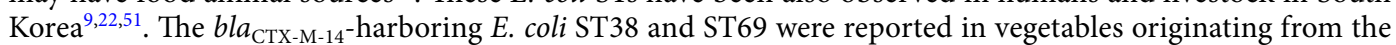
Dominican Republic ${ }^{30}$, India ${ }^{30}$, and China ${ }^{52}$. The E. coli ST10 strains producing CTX-M-type ESBL were often detected in vegetables ${ }^{14,44,53}$. To the best of our knowledge, this is the first report of ESBL-EC ST354 in vegetables. Furthermore, multiple ESBL-ExPEC clones, including ST131, ST405, ST410, and ST393, have been detected in raw vegetables ${ }^{28,30}$. These results suggest the potential roles of vegetables as the reservoir and propagator for ESBL-ExPEC lineages, which increases the threat of human health as a result of direct consumption.

It has been proposed that ESBL genes, plasmids, and strains may circulate among humans, animals, and the environment ${ }^{13,54,55}$. Notably, livestock functions as a primary reservoir of ESBL producers ${ }^{17}$, and the manure of animal feces contaminated with ESBL-ECs can be recycled as organic fertilizer during vegetable production ${ }^{56}$. In addition, ESBL-ECs have been found abundantly in waterbodies, such as surface water, irrigation water, and wastewater ${ }^{57-59}$, which can also be used in agricultural fields. Fecal bacteria can survive for a long time in soil, manure, and water ${ }^{60}$. Thus, fresh vegetables may have acquired resistance through direct or indirect contact with inoculum sources from the contaminated environment.

In conclusion, our findings showed the low prevalence rate of ESBL-ECs in vegetables but the presence of ESBL-ExPECs (ST10, ST38, ST69, and ST354) in stem and leafy, raw vegetables. In particular, the vegetables contaminated with human-associated MDR-ExPEC clones may give rise to further public health concerns and cause epidemics worldwide. Thus, our study emphasizes the importance of intensive monitoring and intervention for antimicrobial resistance from the perspective of the One Health approach, encompassing humans, animals, food produce, and the environment.

\section{Methods}

Study design. A total of 1324 raw vegetables, including 879 leafy, 236 fruit, 170 stem, 37 root, and two other types of vegetables, were collected from the Incheon's two largest agricultural wholesale markets (Sam-San and Guwol markets) between February and October 2018. The countries of origin were South Korea (1318 samples), China (4 samples), and New Zealand (2 samples) (Fig. 1). The samples (30-60 g) were homogenized in a tenfold volume of $E$. coli (EC) broth (Difco Laboratories, Detroit, MI, USA) for 2 min and incubated at $37^{\circ} \mathrm{C}$ overnight. Next, $1 \mathrm{ml}$ of enriched media was added to $9 \mathrm{ml}$ of Tryptone Soya Broth (Oxoid, Basingstoke, UK) supplemented with $0.4 \mathrm{~g} / \mathrm{ml}$ vancomycin (Wako Pure Chemical Industries, Osaka, Japan), followed by incubation at $37^{\circ} \mathrm{C}$ for $4 \mathrm{~h}$. The enrichment was streaked on MacConkey agar containing $2 \mu \mathrm{g} / \mathrm{ml}$ cefotaxime. A non-duplicate colony of pink or reddish hue was picked and further grown on CHROMagar ESBL (CHROMagar, Paris, France) to obtain pure cultures. The E. coli species of isolates was determined using matrix-assisted laser desorption ionization-time of flight mass spectrometry (Bruker Daltonik GmbH, Bremen, Germany) with score values $\geq 2.0$. To confirm ESBL production, the double-disk synergy test was performed using amoxicillin-clavulanic acid $(20 / 10 \mu \mathrm{g})$, cefotaxime $(30 \mu \mathrm{g})$, ceftazidime $(30 \mu \mathrm{g})$, and cefepime $(30 \mu \mathrm{g})$ disks.

Antimicrobial susceptibility testing. Antimicrobial susceptibilities for 22 agents from 15 classes were analyzed by the disk diffusion method on Mueller-Hinton agar (Difco Laboratories) using 6-mm antibiotic disks (Oxoid). The following antimicrobial compounds (disk load) were assessed: gentamicin (GEN $10 \mu \mathrm{g}$ ), amikacin (AMK $30 \mu \mathrm{g}$ ), ertapenem (ETP $10 \mu \mathrm{g}$ ), imipenem (IPM $10 \mu \mathrm{g}$ ), meropenem (MEM $10 \mu \mathrm{g}$ ), cefazolin (CFZ $30 \mu \mathrm{g}$ ), cefotaxime (CTX $30 \mu \mathrm{g}$ ), ceftazidime (CAZ $30 \mu \mathrm{g}$ ), cefepime (FEP $30 \mu \mathrm{g}$ ), cefoxitin (FOX $30 \mu \mathrm{g}$ ), ciprofloxacin (CIP $5 \mu \mathrm{g}$ ), nalidixic acid (NAL $30 \mu \mathrm{g}$ ), trimethoprim-sulfamethoxazole (SXT 1.25/23.75 $\mu \mathrm{g}$ ), tigecycline (TGC $15 \mu \mathrm{g}$ ), aztreonam (ATM $30 \mu \mathrm{g}$ ), ampicillin (AMP $10 \mu \mathrm{g}$ ), piperacillin (PIP $100 \mu \mathrm{g}$ ), amoxicillin-clavulanic acid (AMC 20/10 $\mu \mathrm{g}$ ), ampicillin-sulbactam (SAM 10/10 $\mu \mathrm{g}$ ), chloramphenicol (CHL $30 \mu \mathrm{g}$ ), and tetracycline (TET $30 \mu \mathrm{g}$ ). For the colistin (CST) susceptibility, the minimum inhibitory concentration was determined by the broth microdilution method using the Sensititre system (Thermo Fisher Scientific, Waltham, MA, USA). The phenotypes of resistance, intermediate resistance, and susceptibility were interpreted in accordance with the guidelines of the Clinical and Laboratory Standards Institute document M100-S2 $7^{61}$, except for tigecycline breakpoints, which were interpreted based on the European Committee on Antimicrobial Susceptibility Testing breakpoint tables version $7.1^{62}$. Multidrug resistance (MDR) was defined as non-susceptibility to at least one antimicrobial agent of three or more classes ${ }^{6}$. E. coli ATCC 25922 was used as control strain.

$\boldsymbol{\beta}$-Lactamase genotyping. The pure DNAs of ESBL-ECs were extracted using the G-spin Total DNA Extraction Kit (iNtRON Biotechnology, Seoul, Korea) according to the manufacturer's protocol. To identify $\beta$-lactamase $(b l a)$ genes belonging to $b l a_{\mathrm{CTX}-\mathrm{M}-1}, b l a_{\mathrm{CTX}-\mathrm{M}-2}, b l a_{\mathrm{CTX}-\mathrm{M}-9}, b l a_{\mathrm{CTX}-\mathrm{M}-25}, b l a_{\mathrm{TEM}}$, and $b l a_{\mathrm{SHV}}$, PCR was performed, as previously described ${ }^{22}$. After amplicon sequencing, the resultant sequences were compared with 
those of the $\beta$-lactamase genes in the GenBank database using the NCBI Basic Local Alignment Search Tool (BLAST) (https://blast.ncbi.nlm.nih.gov/Blast.cgi).

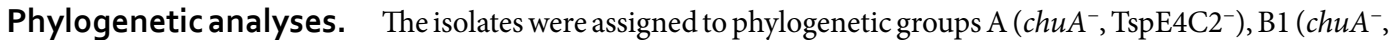
$y j a A^{-}$, TspE4.C2 $\left.2^{+}\right), \mathrm{B} 2\left(c h u A^{+}, y j a A^{+}\right)$, and $\mathrm{D}\left(c h u A^{+}, y j a A^{-}\right)$by a PCR-based assay as previously reported ${ }^{64}$. To determine $E$. coli sequence types (STs), the sequences of seven conserved housekeeping genes ( $a d k$, fum $C, \operatorname{gyr} B$, $i c d, m d h, p u r A$, and $r e c A$ ) were analyzed by multilocus sequence typing (MLST) in accordance with the EnteroBase protocol and database (https://enterobase.warwick.ac.uk; https://enterobase.readthedocs.io/en/latest/) ${ }^{65}$. The maximum-likelihood phylogenetic tree was constructed based on the MLST of the seven housekeeping genes using MEGA X (https://www.megasoftware.net/) with a bootstrap analysis of 1000 replicates.

\section{Data availability}

All data analyzed during this study are included in this published article.

Received: 12 June 2020; Accepted: 4 November 2020

Published online: 12 November 2020

\section{References}

1. Canton, R., Gonzalez-Alba, J. M. \& Galan, J. C. CTX-M enzymes: origin and diffusion. Front. Microbiol. 3, 110. https://doi. org/10.3389/fmicb.2012.00110 (2012).

2. Bevan, E. R., Jones, A. M. \& Hawkey, P. M. Global epidemiology of CTX-M $\beta$-lactamases: temporal and geographical shifts in genotype. J. Antimicrob. Chemother. 72, 2145-2155. https://doi.org/10.1093/jac/dkx146 (2017).

3. Pai, H., Choi, E. H., Lee, H. J., Hong, J. Y. \& Jacoby, G. A. Identification of CTX-M-14 extended-spectrum $\beta$-lactamase in clinical isolates of Shigella sonnei, Escherichia coli, and Klebsiella pneumoniae in Korea. J. Clin. Microbiol. 39, 3747-3749. https://doi. org/10.1128/JCM.39.10.3747-3749.2001 (2001).

4. Lee, H. et al. Antimicrobial resistance of major clinical pathogens in South Korea, May 2016 to April 2017: first one-year report from Kor-GLASS. Euro Surveill. https://doi.org/10.2807/1560-7917.ES.2018.23.42.1800047 (2018).

5. Kim, D. et al. Increasing resistance to extended-spectrum cephalosporins, fluoroquinolone, and carbapenem in gram-negative Bacilli and the emergence of carbapenem non-susceptibility in Klebsiella pneumoniae: analysis of Korean Antimicrobial Resistance Monitoring System (KARMS) data from 2013 to 2015. Ann. Lab. Med. 37, 231-239. https://doi.org/10.3343/alm.2017.37.3.231 (2017).

6. Kim, S., Sung, J. Y., Cho, H. H., Kwon, K. C. \& Koo, S. H. Characteristics of the molecular epidemiology of CTX-M-producing Escherichia coli Isolated from a tertiary hospital in Daejeon, Korea. J. Microbiol. Biotechnol. 26, 1643-1649. https://doi.org/10.4014/ jmb.1603.03063 (2016)

7. Lee, S. G. et al. Spread of CTX-M-type extended-spectrum $\beta$-lactamases among bloodstream isolates of Escherichia coli and Klebsiella pneumoniae from a Korean hospital. Diagn. Microbiol. Infect. Dis. 63, 76-80. https://doi.org/10.1016/j.diagmicrob io.2008.09.002 (2009).

8. Kim, K. G. et al. Prevalence and molecular epidemiology of ESBLs, plasmid-determined AmpC-type $\beta$-lactamases and carbapenemases among diarrhoeagenic Escherichia coli isolates from children in Gwangju, Korea: 2007-16. J. Antimicrob. Chemother. 74, 2181-2187. https://doi.org/10.1093/jac/dkz175 (2019).

9. Park, S. H. et al. Molecular epidemiology of extended-spectrum $\beta$-lactamase-producing Escherichia coli in the community and hospital in Korea: emergence of ST131 producing CTX-M-15. BMC Infect. Dis. 12, 149. https://doi.org/10.1186/1471-2334-12-149 (2012).

10. Yun, K. W., Lee, M. K., Kim, W. \& Lim, I. S. Uropathogenic Escherichia coli ST131 in urinary tract infections in children. Korean J. Pediatr. 60, 221-226. https://doi.org/10.3345/kjp.2017.60.7.221 (2017).

11. Kim, Y. A., Lee, K. \& Chung, J. E. Risk factors and molecular features of sequence type (ST) 131 extended-Spectrum- $\beta$-lactamaseproducing Escherichia coli in community-onset female genital tract infections. BMC Infect. Dis. 18, 250. https://doi.org/10.1186/ s12879-018-3168-8 (2018).

12. Joo, E. J. et al. Fecal carriage of antimicrobial-resistant enterobacteriaceae in healthy Korean adults. J. Microbiol. Biotechnol. 28, 1178-1184. https://doi.org/10.4014/jmb.1801.12060 (2018).

13. Muller, A., Stephan, R. \& Nuesch-Inderbinen, M. Distribution of virulence factors in ESBL-producing Escherichia coli isolated from the environment, livestock, food and humans. Sci. Total Environ. 541, 667-672. https://doi.org/10.1016/j.scitotenv.2015.09.135 (2016).

14. Ben Said, L. et al. Detection of extended-spectrum $\beta$-lactamase (ESBL)-producing Enterobacteriaceae in vegetables, soil and water of the farm environment in Tunisia. Int. J. Food Microbiol. 203, 86-92. https://doi.org/10.1016/j.ijfoodmicro.2015.02.023 (2015).

15. Lee, S. et al. Prevalence of extended-spectrum $\beta$-lactamases in the local farm environment and livestock: challenges to mitigate antimicrobial resistance. Crit. Rev. Microbiol. 46, 1-14. https://doi.org/10.1080/1040841X.2020.1715339 (2020).

16. Geser, N., Stephan, R. \& Hachler, H. Occurrence and characteristics of extended-spectrum $\beta$-lactamase (ESBL) producing Enterobacteriaceae in food producing animals, minced meat and raw milk. BMC Vet. Res. 8, 21. https://doi.org/10.1186/1746-6148-8-21 (2012).

17. Carattoli, A. Animal reservoirs for extended spectrum $\beta$-lactamase producers. Clin. Microbiol. Infect. 14(Suppl 1), 117-123. https ://doi.org/10.1111/j.1469-0691.2007.01851.x (2008).

18. Ye, Q. et al. Characterization of extended-spectrum $\beta$-lactamase-producing enterobacteriaceae from retail food in China. Front. Microbiol. 9, 1709. https://doi.org/10.3389/fmicb.2018.01709 (2018).

19. Campos, J. et al. Microbiological quality of ready-to-eat salads: an underestimated vehicle of bacteria and clinically relevant antibiotic resistance genes. Int. J. Food Microbiol. 166, 464-470. https://doi.org/10.1016/j.ijfoodmicro.2013.08.005 (2013).

20. Kaesbohrer, A. et al. Diversity in prevalence and characteristics of ESBL/pAmpC producing E. coli in food in Germany. Vet. Microbiol. 233, 52-60. https://doi.org/10.1016/j.vetmic.2019.03.025 (2019).

21. Founou, L. L., Founou, R. C. \& Essack, S. Y. Antibiotic resistance in the food chain: a developing country-perspective. Front. Microbiol. 7, 1881. https://doi.org/10.3389/fmicb.2016.01881 (2016).

22. Song, J., Oh, S. S., Kim, J., Park, S. \& Shin, J. Clinically relevant extended-spectrum $\beta$-lactamase-producing Escherichia coli isolates from food animals in South Korea. Front. Microbiol. 11, 604. https://doi.org/10.3389/fmicb.2020.00604 (2020).

23. Kim, Y. J. et al. Genotypic characterization of ESBL-producing E. coli from imported meat in South Korea. Food Res. Int. 107, 158-164. https://doi.org/10.1016/j.foodres.2017.12.023 (2018).

24. Hong, J. S. et al. Clonal spread of extended-spectrum cephalosporin-resistant enterobacteriaceae between companion animals and humans in South Korea. Front. Microbiol. 10, 1371. https://doi.org/10.3389/fmicb.2019.01371 (2019). 
25. Kim, H. S. et al. Prevalence and characterization of extended-spectrum- $\beta$-lactamase-producing Escherichia coli and Klebsiella pneumoniae in ready-to-eat vegetables. Int. J. Food Microbiol. 207, 83-86. https://doi.org/10.1016/j.ijfoodmicro.2015.04.049 (2015).

26. Jang, J. et al. Pathogenic Escherichia coli strains producing extended-spectrum $\beta$-lactamases in the Yeongsan River basin of South Korea. Environ. Sci. Technol. 47, 1128-1136. https://doi.org/10.1021/es303577u (2013).

27. Yeni, F., Yavas, S., Alpas, H. \& Soyer, Y. Most common foodborne pathogens and mycotoxins on fresh produce: a review of recent outbreaks. Crit. Rev. Food Sci. 56, 1532-1544. https://doi.org/10.1080/10408398.2013.777021 (2016).

28. Ortega-Paredes, D., Barba, P., Mena-Lopez, S., Espinel, N. \& Zurita, J. Escherichia coli hyperepidemic clone ST410-A harboring $b l a_{\text {CTX-M-15 }}$ isolated from fresh vegetables in a municipal market in Quito-Ecuador. Int. J. Food Microbiol. 280, 41-45. https://doi. org/10.1016/j.ijfoodmicro.2018.04.037 (2018).

29. Reuland, E. A. et al. Prevalence of ESBL-producing Enterobacteriaceae in raw vegetables. Eur. J. Clin. Microbiol. Infect. Dis. 33, 1843-1846. https://doi.org/10.1007/s10096-014-2142-7 (2014).

30. Zurfluh, K. et al. Extended-spectrum- $\beta$-lactamase-producing Enterobacteriaceae isolated from vegetables imported from the Dominican Republic, India, Thailand, and Vietnam. Appl. Environ. Microbiol. 81, 3115-3120. https://doi.org/10.1128/AEM.00258 -15 (2015).

31. Richter, L., Du Plessis, E. M., Duvenage, S. \& Korsten, L. Occurrence, identification, and antimicrobial resistance profiles of extended-spectrum and AmpC $\beta$-lactamase-producing Enterobacteriaceae from fresh vegetables retailed in Gauteng Province, South Africa. Foodborne Pathog. Dis. 16, 421-427. https://doi.org/10.1089/fpd.2018.2558 (2019).

32. van Hoek, A. H. et al. Prevalence and characterization of ESBL- and AmpC-producing Enterobacteriaceae on retail vegetables. Int. J. Food Microbiol. 204, 1-8. https://doi.org/10.1016/j.ijfoodmicro.2015.03.014 (2015).

33. Denisuik, A. J. et al. Dramatic rise in the proportion of ESBL-producing Escherichia coli and Klebsiella pneumoniae among clinical isolates identified in Canadian hospital laboratories from 2007 to 2016. J. Antimicrob. Chemother. 74, iv64-iv71. https://doi. org/10.1093/jac/dkz289 (2019).

34. Morosini, M. I. et al. Antibiotic coresistance in extended-spectrum- $\beta$-lactamase-producing Enterobacteriaceae and in vitro activity of tigecycline. Antimicrob. Agents Chemother. 50, 2695-2699. https://doi.org/10.1128/AAC.00155-06 (2006).

35. Biedenbach, D. J. et al. Antimicrobial susceptibility and extended-spectrum $\beta$-lactamase rates in aerobic gram-negative bacteria causing intra-abdominal infections in Vietnam: report from the Study for Monitoring Antimicrobial Resistance Trends (SMART 2009-2011). Diagn. Microbiol. Infect. Dis. 79, 463-467. https://doi.org/10.1016/j.diagmicrobio.2014.05.009 (2014).

36. Na, S. H. et al. Antimicrobial resistance and molecular characterization of extended-spectrum $\beta$-lactamase-producing Escherichia coli isolated from ducks in South Korea. Foodborne Pathog. Dis. 16, 799-806. https://doi.org/10.1089/fpd.2019.2644 (2019).

37. Tamang, M. D. et al. Prevalence and molecular characterization of CTX-M $\beta$-lactamase-producing Escherichia coli isolated from healthy swine and cattle. Foodborne Pathog. Dis. 10, 13-20. https://doi.org/10.1089/fpd.2012.1245 (2013).

38. Park, H., Kim, J., Ryu, S. \& Jeon, B. Predominance of $b l a_{\mathrm{CTX}-\mathrm{M-65}}$ and $b l a_{\mathrm{CTX}-\mathrm{M}-55}$ in extended-spectrum $\beta$-lactamase-producing Escherichia coli from raw retail chicken in South Korea. J. Glob. Antimicrob. Resist. 17, 216-220. https://doi.org/10.1016/j. jgar.2019.01.005 (2019).

39. Sun, Y. et al. High prevalence of $b l a_{\mathrm{CTX}-\mathrm{M}}$ extended-spectrum $\beta$-lactamase genes in Escherichia coli isolates from pets and emergence of CTX-M-64 in China. Clin. Microbiol. Infect. 16, 1475-1481. https://doi.org/10.1111/j.1469-0691.2010.03127.x (2010).

40. Huang, Y., Zeng, L., Doi, Y., Lv, L. \& Liu, J. H. Extended-spectrum $\beta$-lactamase-producing Escherichia coli. Lancet Infec.t Dis. 20, 404-405. https://doi.org/10.1016/S1473-3099(20)30115-8 (2020).

41. Harada, K., Nakai, Y. \& Kataoka, Y. Mechanisms of resistance to cephalosporin and emergence of O25b-ST131 clone harboring CTX-M-27 $\beta$-lactamase in extraintestinal pathogenic Escherichia coli from dogs and cats in Japan. Microbiol. Immunol. 56, 480-485. https://doi.org/10.1111/j.1348-0421.2012.00463.x (2012).

42. Nakamura, A. et al. Analysis of molecular epidemiologic characteristics of extended-spectrum $\beta$-lactamase (ESBL)-producing Escherichia coli colonizing feces in hospital patients and community dwellers in a Japanese city. J. Infect. Chemother. 22, 102-107. https://doi.org/10.1016/j.jiac.2015.11.001 (2016).

43. Nguyen, V. T. et al. Limited contribution of non-intensive chicken farming to ESBL-producing Escherichia coli colonization in humans in Vietnam: an epidemiological and genomic analysis. J. Antimicrob. Chemother. 74, 561-570. https://doi.org/10.1093/ jac/dky506 (2019).

44. Oh, S. S., Song, J., Kim, J. \& Shin, J. Increasing prevalence of multidrug-resistant $m c r$-1-positive Escherichia coli isolates from fresh vegetables and healthy food animals in South Korea. Int. J. Infect. Dis. 92, 53-55. https://doi.org/10.1016/j.ijid.2019.12.025 (2020).

45. Rao, L. et al. Increasing prevalence of extended-spectrum cephalosporin-resistant Escherichia coli in food animals and the diversity of CTX-M genotypes during 2003-2012. Vet. Microbiol. 172, 534-541. https://doi.org/10.1016/j.vetmic.2014.06.013 (2014).

46. Zhang, J. et al. Nationwide high prevalence of CTX-M and an increase of CTX-M-55 in Escherichia coli isolated from patients with community-onset infections in Chinese county hospitals. BMC Infect. Dis. 14, 659. https://doi.org/10.1186/s12879-014-0659-0 (2014).

47. Kiratisin, P. et al. The emergence of a novel ceftazidime-resistant CTX-M extended-spectrum $\beta$-lactamase, CTX-M-55, in both community-onset and hospital-acquired infections in Thailand. Diagn. Microbiol. Infect. Dis. 58, 349-355. https://doi.org/10.1016/j. diagmicrobio.2007.02.005 (2007).

48. Johnson, J. R., Delavari, P., Kuskowski, M. \& Stell, A. L. Phylogenetic distribution of extraintestinal virulence-associated traits in Escherichia coli. J. Infect. Dis. 183, 78-88. https://doi.org/10.1086/317656 (2001).

49. Manges, A. R. et al. Global extraintestinal pathogenic Escherichia coli (ExPEC) lineages. Clin. Microbiol. Rev. https://doi. org/10.1128/CMR.00135-18 (2019).

50. Singer, R. S. Urinary tract infections attributed to diverse ExPEC strains in food animals: evidence and data gaps. Front. Microbiol. 6, 28. https://doi.org/10.3389/fmicb.2015.00028 (2015).

51. Kim, J. et al. Characterization of IncF plasmids carrying the bla $a_{\mathrm{CTX}-\mathrm{M}-14}$ gene in clinical isolates of Escherichia coli from Korea. J. Antimicrob. Chemother. 66, 1263-1268. https://doi.org/10.1093/jac/dkr106 (2011).

52. Luo, J. et al. Emergence of $m c r-1$ in Raoultella ornithinolytica and Escherichia coli isolates from retail vegetables in China. Antimicrob. Agents Chemother. https://doi.org/10.1128/AAC.01139-17 (2017).

53. Freitag, C. et al. Occurrence and characterisation of ESBL-encoding plasmids among Escherichia coli isolates from fresh vegetables. Vet. Microbiol. 219, 63-69. https://doi.org/10.1016/j.vetmic.2018.03.028 (2018).

54. Leverstein-van Hall, M. A. et al. Dutch patients, retail chicken meat and poultry share the same ESBL genes, plasmids and strains. Clin. Microbiol. Infect. 17, 873-880. https://doi.org/10.1111/j.1469-0691.2011.03497.x (2011).

55. Hammerum, A. M. et al. Characterization of extended-spectrum $\beta$-lactamase (ESBL)-producing Escherichia coli obtained from Danish pigs, pig farmers and their families from farms with high or no consumption of third- or fourth-generation cephalosporins. J. Antimicrob. Chemother. 69, 2650-2657. https://doi.org/10.1093/jac/dku180 (2014).

56. Gao, L. et al. Application of swine manure on agricultural fields contributes to extended-spectrum $\beta$-lactamase-producing Escherichia coli spread in Taian China. Front. Microbiol. 6, 313. https://doi.org/10.3389/fmicb.2015.00313 (2015).

57. Araujo, S. et al. Characterization of antibiotic resistant and pathogenic Escherichia coli in irrigation water and vegetables in household farms. Int. J. Food Microbiol. 257, 192-200. https://doi.org/10.1016/j.ijfoodmicro.2017.06.020 (2017).

58. Franz, E., Veenman, C., van Hoek, A. H., de Roda Husman, A. \& Blaak, H. Pathogenic Escherichia coli producing extendedspectrum $\beta$-lactamases isolated from surface water and wastewater. Sci. Rep. 5, 14372. https://doi.org/10.1038/srep14372 (2015). 
59. Jorgensen, S. B. et al. A comparison of extended spectrum $\beta$-lactamase producing Escherichia coli from clinical, recreational water and wastewater samples associated in time and location. PLoS ONE 12, e0186576. https://doi.org/10.1371/journal.pone.0186576 (2017).

60. Holvoet, K., Sampers, I., Callens, B., Dewulf, J. \& Uyttendaele, M. Moderate prevalence of antimicrobial resistance in Escherichia coli isolates from lettuce, irrigation water, and soil. Appl. Environ. Microbiol. 79, 6677-6683. https://doi.org/10.1128/AEM.01995 -13 (2013).

61. Clinical and Laboratory Standards Institute. Performance Standards for Antimicrobial Susceptibility Testing. 27th edn. CLSI supplement M100. Wayne, PA (2017).

62. The European Committee on Antimicrobial Susceptibility Testing. Breakpoint Tables for Interpretation of MICs and Zone Diameters. Version 7.1 (2017).

63. Magiorakos, A. P. et al. Multidrug-resistant, extensively drug-resistant and pandrug-resistant bacteria: an international expert proposal for interim standard definitions for acquired resistance. Clin. Microbiol. Infect. 18, 268-281. https://doi.org/10.111 1/j.1469-0691.2011.03570.x (2012).

64. Clermont, O., Bonacorsi, S. \& Bingen, E. Rapid and simple determination of the Escherichia coli phylogenetic group. Appl. Environ. Microbiol. 66, 4555-4558. https://doi.org/10.1128/aem.66.10.4555-4558.2000 (2000).

65. Wirth, T. et al. Sex and virulence in Escherichia coli: an evolutionary perspective. Mol. Microbiol. 60, 1136-1151. https://doi.org/ 10.1111/j.1365-2958.2006.05172.x (2006).

\section{Acknowledgements}

This work was supported by the Korea Centers for Disease Control and Prevention (2017ER540301), the Basic Science Research Program through the National Research Foundation (NRF) of Korea funded by the Ministry of Education (2018R1A6A1A03025523), and an Inha University Research Grant (2020).

\section{Author contributions}

J.S. contributed to the conception and design of this study; J.H.S., S.-S.O., and J.K. collected the samples and performed the experiments; J.H.S. and J.S. analyzed the data; J.S. wrote the manuscript. All authors reviewed the manuscript.

\section{Competing interests}

The authors declare no competing interests.

\section{Additional information}

Correspondence and requests for materials should be addressed to J.S.

Reprints and permissions information is available at www.nature.com/reprints.

Publisher's note Springer Nature remains neutral with regard to jurisdictional claims in published maps and institutional affiliations.

Open Access This article is licensed under a Creative Commons Attribution 4.0 International License, which permits use, sharing, adaptation, distribution and reproduction in any medium or format, as long as you give appropriate credit to the original author(s) and the source, provide a link to the Creative Commons licence, and indicate if changes were made. The images or other third party material in this article are included in the article's Creative Commons licence, unless indicated otherwise in a credit line to the material. If material is not included in the article's Creative Commons licence and your intended use is not permitted by statutory regulation or exceeds the permitted use, you will need to obtain permission directly from the copyright holder. To view a copy of this licence, visit http://creativecommons.org/licenses/by/4.0/.

(C) The Author(s) 2020 